\title{
Equations of temperature graphics of a heating point with a two-stage scheme of heat exchangers of hot water supply
}

\author{
Tatyana Rafalskaya* \\ Novosibirsk State University of Architecture and Civil Engineering (Sibstrin), Leningradskaya, 113, \\ 630008 Novosibirsk, Russia
}

\begin{abstract}
The temperature of the water returned to the heating network from consumers largely determines the energy efficiency of the heat supply system. It depends on a number of parameters: outside air temperature, hot water supply heaters connection scheme, daily water consumption in the hot water supply system. The calculation of this temperature is usually performed numerically, which makes it difficult to control the modes of the heat supply system. From a practical point of view, a simpler toolkit is needed. In this paper, equations are proposed that allow directly determining the change in the heat output of heat exchangers depending on the outside air temperature and the temperature of the network water returned to the heating network. These equations are obtained on the basis of systematic modeling of variable operating modes of the heat supply system, using the method previously proposed by the author. The operating characteristics of the heat station are taken into account by the coefficients of the equations, for the determination of which the calculation formulas were obtained. The equations used are valid for substations with a twostage mixed scheme of hot water supply heaters in the mode of maximum water consumption.
\end{abstract}

\section{Introduction}

Regulation of heat flows and flow rates of network water in the heat supply system is carried out using temperature graphics $[1,2]$. In order to be able to identify ineffective modes of joint operation of heating and hot water supply systems at the design stage and to clarify the area and performance of heat exchangers, it is necessary to calculate the water temperatures after each stage of heat exchangers and returned to the heat supply network, which determined the relevance of this work.

The problems of determining the dependence of the parameters of heat supply systems with a given heat load on the temperature graph for regulating the supply of heat energy were raised in [3-7]. But papers [4, 5] are devoted to the determination of the water temperature in the supply line of the heating network, corresponding to the optimal ratio of heat losses and the material characteristics of the heat supply network; the temperature of

\footnotetext{
${ }^{*}$ Corresponding author: rafalskaya.ta@yandex.ru
} 
the water returned to the heat supply network was not determined. In [6], the additional flow of heating water is determined when the temperature of the water in the supply line of the heat supply network and the temperature of the return water after the heating system decreases, but the effect of the load of hot water supply on the temperature of the return water in the heat supply network is not taken into account. An interesting approach to modeling thermohydraulic modes of heating points, based on the concept of object-oriented modeling by methods of the theory of hydraulic circuits, proposed in [8]. However, in [8], the calculation of a single-stage parallel scheme for connecting a heat exchanger is given, ie. the associated heat supply to heating and hot water supply systems is not taken into account. The calculation of variable modes of heating point with a coupled heat supply can be performed only by the method of successive approximations [2, 5]. The calculation method is given in the author's work [9]. At the same time, it should be noted that the calculation according to the methods of both [8] and [9] is time consuming and can only be performed on a computer, which complicates the design of heat points schemes and the construction of a control system. In [10], dependences are proposed for determining the outside air temperature and the return water temperature only at the break point of the heating temperature graph. The purpose of this work is to obtain equations for constructing temperature graphs over the entire range of outdoor temperatures during the heating period.

\section{Materials and Methods}

With a qualitative method of regulating the heat load, depending on the outside air temperature, the temperatures of the network water in the supply line of the heat supply network are calculated

$$
t_{p 1}\left(t_{e x t}\right)=t_{i n t}+\Delta t_{\mathrm{oc}}\left(\bar{Q}_{\mathrm{o}}\right)^{0,8}+\left(\delta t_{c}-0,5 \theta_{c}\right) \bar{Q}_{\mathrm{o}} \geq t_{p 1 f}
$$

and in the return line of the heating system [11]

$$
t_{h 2}^{h s}\left(t_{e x t}\right)=t_{i n t}+\Delta t_{\mathrm{oc}}\left(\bar{Q}_{\mathrm{o}}\right)^{0,8}-0,5 \theta_{c} \bar{Q}_{\mathrm{o}}
$$

where $t_{\text {int }}$ - indoor air temperature; $\bar{Q}_{\mathrm{o}}=\left(t_{\text {int }}-t_{\text {ext }}\right) /\left(t_{\text {int }}-t_{\text {ext. }}\right)$ - required relative heat consumption for heating; $t_{\text {ext.c }}$ - design outdoor temperature for heating design; $\Delta t_{\mathrm{oc}}=\left(t_{h 1 c}^{h s}+t_{h 2 c}^{h s}\right) / 2-t_{\text {int }}$ - the calculated temperature head when mixing water in the mixing device of the heating point, at the calculated water temperatures in the supply $t_{h 1 c}^{h s}$ and in return $t_{h 2 c}^{h s}$ heating mains; $\delta t_{\mathrm{oc}}=t_{p 1 c}-t_{p 2 c}$ - calculated temperature difference of heating water; $\theta_{c}=t_{h 1 c}^{h s}+t_{h 2 c}^{h s}$ - calculated temperature difference of water in the heating system; $t_{p 1 f}-$ temperature of the water in the supply line of the heating system at the break point of the temperature graph.

These dependencies are used when calculating temperature graphs of quality regulation, for example, in Russia, in China [12, 13].

In two-stage schemes for connecting of hot water supply heat exchangers at heating points (HP), the return water after the heating system is mixed with water after the second stage hot water supply heater and enters the first stage of the heater, and then - into the heating network. Thus, the temperature of the water returned to the heat supply network will depend on the outside temperature, the connection scheme of the hot water supply heat exchangers, and daily water consumption in the hot water supply system (HWS). Therefore, 
it is rather difficult to determine it by calculation using a simple formula similar to formulas (1) and (2) [4].

At the same time, the temperature of the return network water is an important indicator of the energy efficiency of the heat supply system, since it shows the degree of utilization of the available heat capacity. Overestimation of the return water temperature is often observed during the operation of district heating systems, especially during the transitional period of the heating season $[14,15]$. This reduces the generation of electrical energy, increases fuel consumption for the production of thermal energy and reduces the overall efficiency of the heat source $[14,15]$.

According to the method proposed in [9] for calculating variable modes of heating points with associated heat supply to heating and hot water supply systems, an analysis was made of changes in temperatures and flow rates of network water during the heating period for the heating graph of central regulation, including with a cut, in the mode of maximum water consumption in the hot water supply system. The results of the computational study made it possible to establish the main regularities of changes in temperatures and flow rates of network water in a HP and obtain analytical dependences for their determination.

To determine the temperature of the heat supply network returned to the return line of the heating network after the I stage of HWS heater, the following expression was obtained

$$
t_{p 2}\left(t_{e x t}\right)=t_{h 1}^{\mathrm{I}}+\Delta t_{f}^{\mathrm{I}}\left[\frac{Q_{h}^{\mathrm{I}}\left(t_{e x t}\right)}{Q_{h f}^{\mathrm{I}}}\right]^{-A}+B\left(t_{p 2 f}^{h s}-t_{p 2 f}\right)\left[\frac{Q_{h}^{\mathrm{I}}\left(t_{e x t}\right)}{Q_{h f}^{\mathrm{I}}}\right]^{C},
$$

where $t_{h 1}^{\mathrm{I}}$ - cold water temperature; $\Delta t_{f}^{\mathrm{I}}$ - average temperature difference between the mains water in the I stage of HWS heater at the break point of the temperature graph; $t_{p 2 f}^{h s}$ and $t_{p 2 f}$ - return water temperature after the heating system and after the first stage of HWS heater at the break point of the temperature graph, respectively; $A, B, C$ - constant coefficients. The coefficient $A$ depends on calculated water temperature in the heating network $t_{p 1 c}$, temperature of the lower cut (break) $t_{\text {lower }}^{\text {cut }}$ and $\psi=Q_{h} / Q_{\text {omax }}$; coefficient $B$ depends on $t_{p 1 c}, \psi$ and heat loss coefficient $K_{t}$; coefficient $C$ depends on $t_{\text {lower }}^{\text {cut }}, \psi$ and $K_{t}$. These coefficients can be determined by the following formulas:

$$
\begin{gathered}
A=\left[\left(1,65-0,01 t_{p 1 c}\right)+(1-\psi)\left(0,5+0,004 t_{p 1 c}\right)\right]+\left(t_{\text {lower }}^{\text {cut }}-70\right) \frac{0,35+(1-\psi)\left(0,008 t_{p 1 c}-0,583\right)}{5},(4) \\
B=\left[\left(5-0,028 t_{p 1 c}\right)+(1-\psi)\left(19,3-0,1 t_{p 1 c}\right)\right]+\left(K_{t}-0,2\right) \frac{1,1-0,006 t_{p 1 c}+(1-\psi)\left(0,013 t_{p 1 c}-2\right)}{0,15},(5) \\
C=\left(4,05-0,25 \psi-0,04_{\text {lower }}^{\text {cut }}\right)-\left(K_{t}-0,2\right) \frac{0,5(1-\psi)+\left(t_{\text {lower }}^{\text {cut }}-70\right)(0,08 \psi-0,024)}{0,15}
\end{gathered}
$$

$Q_{h f}^{\text {I }}-$ calculated thermal power of the I stage of HWS heater; the change in heat output depending on can be determined by the following equation:

$$
Q_{h}^{\mathrm{I}}\left(t_{e x t}\right)=Q_{h c}^{\mathrm{I}} D\left(\frac{2 t_{p 1}^{r e q}\left(t_{e x t}\right)-t_{p 1}\left(t_{e x t}\right)}{E}\right)^{F},
$$


where $t_{p 1}^{r e q}\left(t_{\text {ext }}\right)$ - required water temperature in the supply line of the heat supply network according to the heating graph (without breaking point in the graph to ensure the heat output of the HWS during the transitional period of the heating season and without cuts at low outside temperatures); $t_{p 1}\left(t_{\text {ext }}\right)$ - water temperature in the supply line of the heat supply network according to the heating graph with a break point and / or with a cut; $D, E$, $F-$ constant coefficients. The coefficient $D$ depends on $t_{p 1 c}, K_{t}$ and $\psi$; coefficient $E$ depends on $t_{p 1 c}$ only; coefficient $F$ depends on $t_{\text {upper }}^{\text {cut }}$ and $t_{\text {lower }}^{\text {cut }}$. For graphics without an upper cut $t_{u p p e r}^{\text {cut }}=t_{p 1 c}$. To determine these coefficients, the following formulas were obtained:

$$
\begin{gathered}
D=\left[1,05-(\psi-0,2) \frac{0,003 t_{p 1 c}-0,15}{0,8}\right]+\left(0,35-K_{t}\right) \frac{0,02+0,0125(\psi-0,2)}{0,15}, \\
E=45+0,2 t_{p 1 c} \\
F=0,77+0,08 \frac{t_{p 1 c}-t_{\text {upper }}^{c u t}}{t_{p 1 c}-100}-\left(t_{\text {lower }}^{\text {cut }}-70\right)\left(0,007-0,005 \frac{t_{p 1 c}-t_{\text {upper }}^{c u t}}{t_{p 1 c}-100}\right)
\end{gathered}
$$

The temperature of the network water at the inlet to the HWS heat exchanger of the I stage can be found using the following equation:

$$
t_{p 1}^{\mathrm{I}}\left(t_{e x t}\right)=0,5 t_{h 2 f}^{\mathrm{I}}+\Delta t_{f}^{\mathrm{I}}\left[\frac{Q_{h}^{\mathrm{I}}\left(t_{e x t}\right)}{Q_{h f}^{\mathrm{I}}}\right]^{-G}+H\left(t_{p 2 f}^{h s}-t_{2 f}\right)\left[\frac{Q_{h}^{\mathrm{I}}\left(t_{e x t}\right)}{Q_{h f}^{\mathrm{I}}}\right]^{I},
$$

where $t_{h 2 f}^{\mathrm{I}}$ - temperature of heated (tap) water after the I stage of HWS heat exchanger; $G, H, I$ - constant coefficients. The coefficient $G$ depends on $t_{p 1 c}, t_{\text {lower }}^{\text {cut }}$ и $\psi$; coefficient $H$ depends on от $t_{p 1 c}, \psi$ и $K_{t}$; coefficient $I$ depends on $t_{\text {lower }}^{\text {cut }}$ и $\psi$. You can define them by the following expressions:

$$
\begin{aligned}
& G=\left\lfloor\left(1,65-0,01 t_{p 1 c}\right)+(1-\psi)\left(0,25+0,01 t_{p 1 c}\right)\right\rfloor+ \\
& +\left(t_{\text {lower }}^{\text {cut }}-70\right) \frac{0,25+0,002 t_{p 1 c}+(1-\psi)\left(0,01 t_{p 1 c}+1,42\right)}{5} \\
& H=\left\lfloor\left(2,32-0,007 t_{p 1 c}\right)+(1-\psi)\left(6,1-0,03 t_{p 1 c}\right)\right\rfloor+ \\
& +\left(K_{t}-0,2\right) \frac{0,52-0,002 t_{p 1 c}+(1-\psi) 0,03 t_{p 1 c}}{0,15} \\
& I=9,45-0,1 t_{\text {lower }}^{\text {cut }}+(1-\psi)\left(5,13-0,063_{\text {lower }}^{\text {cut }}\right)
\end{aligned}
$$

To determine the temperature of the network water at the outlet from the II stage of HWS heat exchanger, the following equation was obtained:

$$
t_{p 2}^{\mathrm{II}}\left(t_{e x t}\right)=65-\Delta t_{f}^{\mathrm{II}}\left[\frac{Q_{h}^{\mathrm{II}}\left(t_{e x t}\right)}{Q_{h f}^{\mathrm{II}}}\right]^{L}+M\left(t_{\text {lower }}^{\text {cut }}-\Delta t_{f}^{\mathrm{II}}\right)\left[\frac{Q_{h}^{\mathrm{II}}\left(t_{\text {ext }}\right)}{Q_{h f}^{\mathrm{II}}}\right]^{N_{p s}},
$$


where $Q_{h f}^{\mathrm{II}}$ - design thermal power of the II stage of HWS heat exchanger; change in heat output of the II stage of HWS heat exchanger depending on $t_{e x t}$ is defined as the difference between the calculated thermal power of hot water supply $Q_{h f}$ and the heat power of the I stage of HWS heat exchanger, determined by the formula (7):

$$
Q_{h}^{\mathrm{II}}\left(t_{e x t}\right)=Q_{h f}-Q_{h}^{\mathrm{I}}\left(t_{\text {ext }}\right)
$$

$L, M, N$ - constant coefficients. The coefficient $L$ depends on $\psi$ and $K_{t}$; coefficient $M$ depends on $t_{p 1 c}, t_{\text {lower }}^{\text {cut }}$ and $\psi$; coefficient $N$ depends on $\psi$ and $K_{t}$. To determine them, the following equations were obtained:

$$
\begin{gathered}
L=1,55-0,25 \psi-\left(K_{t}-0,2\right)(0,33 \psi+1,67) . \\
M=\left\lfloor\left(1,38-0,008 t_{p 1 c}\right)-(1-\psi)\left(0,32+0,003 t_{p 1 c}\right)\right\rfloor+ \\
+\left(K_{t}-0,2\right) \frac{1,48-0,007 t_{p 1 c}-(1-\psi)\left(0,37-0,009 t_{p 1 c}\right)}{0,15}, \\
N=1,33-1,13 \psi-\left(K_{t}-0,2\right)(6,67 \psi-2) .
\end{gathered}
$$

\section{Results and Discussion}

In fig. 1 shows the results of calculating the thermal power of the I stage of HWS heat exchanger according to the formula (7) in comparison with the calculation according to the method [9] for some variants of the calculated characteristics of the heat point operation shown in Fig. 2, 3. As can be seen from Fig. 1, the greatest deviation is observed at large $\psi$ ratios and low values $\overline{Q_{0}}$, i.e. at high outside air temperatures and the more, the lower the calculated water temperature in the supply line of the heat supply network. The deviation is due to the fact that the area of operation of the heat supply system with a constant water temperature increases (not according to the heating graph). However, even with $\psi=1.0$ and $t_{p 1 c}=100^{\circ} \mathrm{C}$ (variant 1 ), this deviation does not exceed $8 \%$, which is acceptable for engineering calculations.

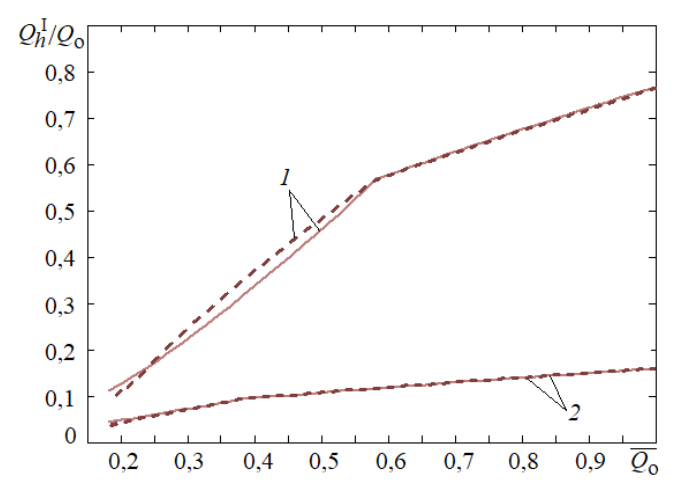

Fig. 1. Dependence of the relative thermal power of the 1st stage heat exchanger on the relative heating power. Solid lines - calculation by the method [9], dashed lines - by formula (7). Calculation options: 1 - see fig. $2 ; 2-$ see fig. 3. 
In fig. Figures 2-7 show the results of calculating the network water temperatures by the method [9] (solid lines) and by formulas (3), (11) and (15) (dashed and dash-dotted lines) for heating points with different design characteristics.
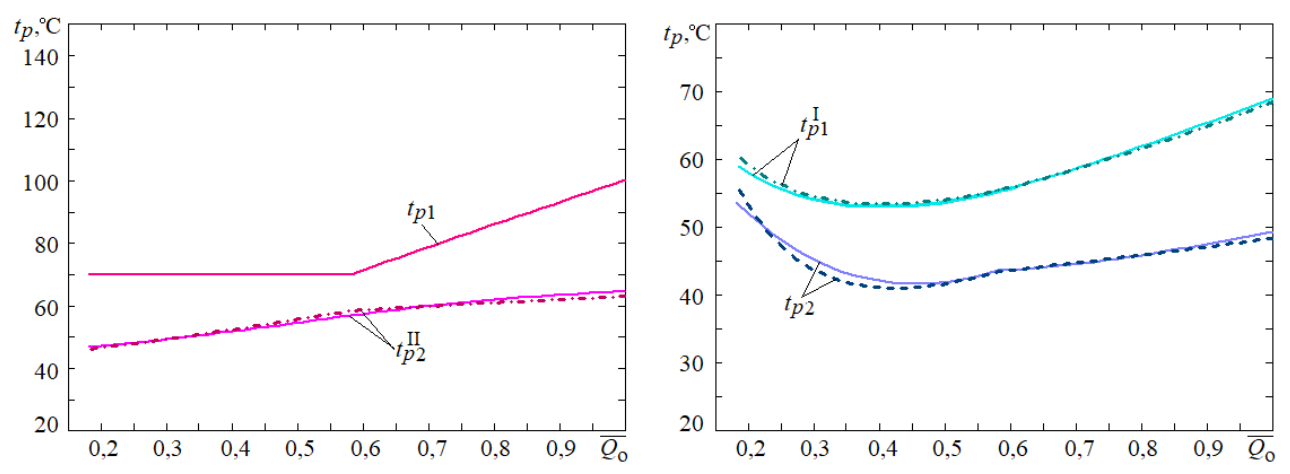

Fig. 2. Supply water temperatures for the design characteristics of the heating point: $t_{p 1 c}=100^{\circ} \mathrm{C} ; t_{\text {lower }}^{\text {cut }}=70^{\circ} \mathrm{C} ; \psi=1.0 ; K_{t}=0.2$.
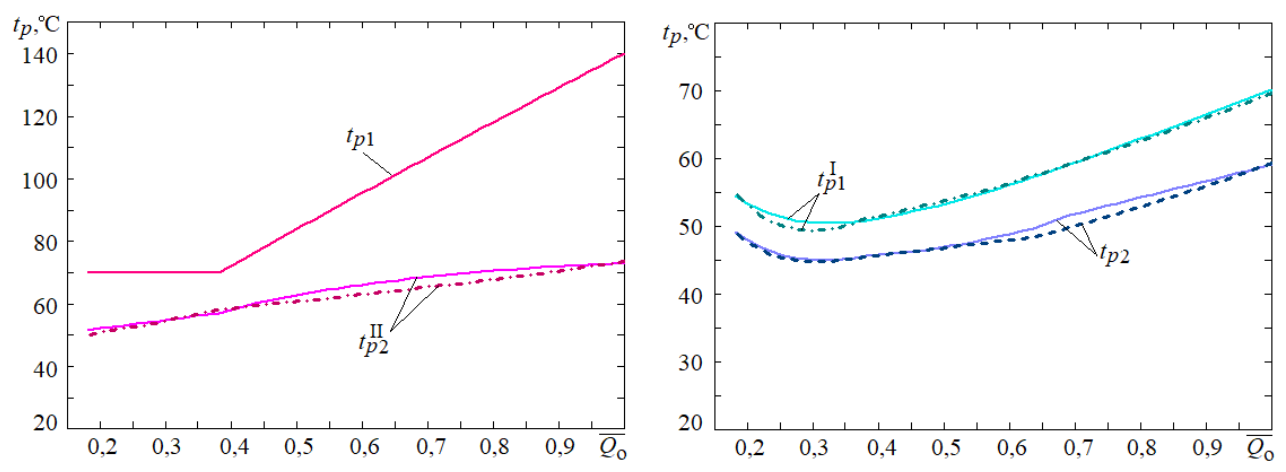

Fig. 3. Supply water temperatures for the design characteristics of the heating point: $t_{p 1 c}=140^{\circ} \mathrm{C} ; t_{\text {lower }}^{\text {cut }}=70^{\circ} \mathrm{C} ; \psi=0.2 ; K_{t}=0.35$.

\section{Conclusion}

The calculation of variable modes of coupled heat exchangers is quite laborious and can only be performed on a computer; the calculation results are the numerical dependences of variable temperatures and flow rates of heat carriers, which complicates their regulation. The main regularities of changes in temperatures and flow rates of network water in a heating station are established and analytical dependences are obtained for their determination without using the method of successive approximations. The obtained equations are valid for the heating graph of central regulation, including with a cuts, in the mode of maximum water consumption in the hot water supply system.

\section{References}

1. W. Hai, W. Haiying, Z. Tong, J., Energy Conversion and Management, 147, 174 (2017)

2. E. Kaubasi, H. Kurt, J., Engineering Science and Technology, 70 (2018) 
3. Ya.A. Vladimirov, N.T.Amosov, V.V. Sergeev, Proc. Int. Conf. Science week StPPU, 14 (2016)

4. V.A. Sednin, A.V. Sednin, M.L. Bogdanovich, J., News of higher educational institutions and energy associations of the CIS, 4, 55 (2009)

5. S.G. Kultyaev, J. Internet journal «Naukovedenie», 9(2), (2017), http://naukovedenie.ru/

6. S.V. Panferov, V.I. Panferov, J. Bul. of SUSU. Ser. Construction Engineering and Architecture, 18(3), 60 (2018)

7. T.A. Rafalskaya, J. Thermal Engineering, 11(66), 858 (2019)

8. N.N. Novitsky, Z.I. Shalaginova, E.A. Mikhailovsky, J. Bul. of Irkutsk State Technical University, 21(9), 157 (2017)

9. T.A. Rafalskaya, V.Ya. Rudyak, J. Phys.: Conf. Ser. 1565012005 (2020)

10. D.N. Kitaev, G.N. Martynenko, A.V. Loboda, J. Scientific Journal of Construction and Architecture, 3(55), 21 (2019)

11. E.Ya. Sokolov, Publishing house MEI, Heating and Heat Networks (2001)

12. H. Pieper, T.S. Ommen, W.B. Markussen, B. Elmegaard, Proc. of ECOS 2017: 30th Intern. Conf. of Efficiency, Cost, Optimization, Simulation and Environmental Impact of Energy Systems, Optimal usage of low temperature sources to supply district heating by heat pumps, 191 (2017)

13. S. Xiaofang, W. Peng, R. Panhong, Z. Hua, MATEC Web of Conferences 5406004 , (2016)

14. R.Sh Mansurov, T.A. Rafalskaya, D.I. Efimov, E3S Web of Conferences 97, 06007 (2019)

15. P.V. Rotov, M.E. Orlov, V.I. Sharapov, J. Proc. of the higher educational institutions. Energy Sector Problems, 5-6, 3 (2014) 